\title{
Blood pressure, heart rate, and skin temperature in preterm infants: associations with periventricular haemorrhage
} S W D’Souza, H Janakova, D Minors, R Suri, J Waterhouse, G Appleton, C Ramesh,
D G Sims, M L Chiswick

\begin{abstract}
The mean arterial blood pressure (MABP), heart rate, and skin temperature were monitored every 15 minutes in the first 10 days after birth in 34 preterm infants, gestational age 24 to 33 weeks. Ultrasound brain scans carried out daily showed that a periventricular haemorrhage (PVH) occurred in a subgroup of infants $(n=15)$ of lower birthweight and gestational age. In infants without PVH the daily median of MABP increased with birthweight and postnatal age; that of heart rate was not affected by postnatal age, body weight, or gestational age; and that of skin temperature showed a slight fall with postnatal age. In infants with PVH, on or before the day of PVH, daily medians of MABP and skin temperature were not significantly different from those of infants without PVH, but the daily median of heart rate tended to be slightly higher. The percentage of positive correlations between the 9615 minute values per day for heart rate and MABP increased with postnatal age and with birthweight, but did not differ in infants who developed a PVH. The coefficient of variation (CV) of the $96 \quad 15$ minute values for MABP tended to be higher in infants on the day of PVH, and a similar trend was apparent on the day before.
\end{abstract}

The processes of development of blood pressure, heart rate, and skin temperature are similar in infants with or without PVH but at lower gestational ages altered blood pressure control may cause brain haemorrhage.

(Arch Dis Child 1995; 72: F162-F167)

Keywords: periventricular haemorrhage, blood pressure, heart rate, temperature.

Studies in very low birthweight infants have shown that in the first 48 to 96 hours of life blood pressure is influenced by birthweight and postnatal age. ${ }^{1-3} \mathrm{~A}$ rise in blood pressure was associated with an increase in birthweight and an increase in postnatal age. The risk of a periventricular haemorrhage (PVH) was greater in infants who had respiratory distress syndrome and required ventilation. ${ }^{4-6} \mathrm{PVH}$ has been associated with changes in cerebral blood flow velocity, which reflected changes in systemic blood pressure. ${ }^{7}$ The possibility that changes in systemic blood pressure may affect the cerebral circulation in a 'pressure passive state' therefore has implications for the aetiology of PVH. ${ }^{89}$

Most haemorrhages seem to start in the germinal layer matrix, as thin-walled blood vessels are vulnerable to damage due to disturbances in perfusion, caused by an increase in blood pressure, ${ }^{10}$ a fall in blood pressure, ${ }^{11}$ or a fluctuating blood pressure. ${ }^{7}$ In such infants breathing asynchronously with the ventilator, Rennie et al reported a significantly greater variability in cerebral blood flow velocity but found no characteristic wave pattern in those at risk from PVH. ${ }^{12}$ In ventilated infants changes in blood pressure may occur as a result of handling during nursing care procedures ${ }^{13}$ and due to a pneumotho$\operatorname{rax}^{14}$ which may lead to a PVH. Compared with infants who do not develop a PVH, those at risk were reported to spend a significantly greater proportion of time with wide swings in mean blood pressure - that is, with a higher coefficient of variation (CV) in blood pressure. ${ }^{37}$ This finding is not consistent with a study by Miall-Allen et al, ${ }^{14}$ who showed that a reduction in the CV for systolic blood pressure preceded the development of a PVH.

In this study we monitored at 15 minute intervals, for three to 10 days in the first 10 days after birth, the mean arterial blood pressure (MABP), heart rate, and skin temperature in an unselected group of very low birthweight infants, to investigate a link with the development of a PVH. As baroreceptor reflexes might be poorly developed and this might influence the development of a PVH we also investigated the association between heart rate and MABP. Skin temperature was measured as we expected changes in tissue blood flow after birth to support transitional changes in metabolism in order to maintain body temperature. ${ }^{15}$ The infants were followed up after leaving hospital to investigate the incidence of subsequent neurological abnormality.

\section{Methods}

Between February 1992 and March 1993 a total of 34 preterm infants admitted to the Neonatal Medical Unit at St Mary's Hospital, Manchester, were included in the study. Their gestational ages ranged from 24 to 33 weeks (table). All had the idiopathic respiratory distress syndrome and received intermittent positive pressure ventilation. None had a PVH on an ultrasound brain scan immediately after 
Clinical conditions in first 10 days of life in relation to development of PVH ${ }^{\star}$

\begin{tabular}{|c|c|c|c|}
\hline Conditions & $\begin{array}{l}\text { With PVH } \\
(n=15)\end{array}$ & $\begin{array}{l}\text { Without PVH } \\
(n=19)\end{array}$ & $\stackrel{p}{\text { Value }}$ \\
\hline \multicolumn{4}{|l|}{ Site of delivery } \\
\hline St Mary's Hospital & 5 & 9 & NS \\
\hline Another hospital & 10 & 10 & \\
\hline \multicolumn{4}{|l|}{ Mode of delivery } \\
\hline Vaginal & 11 & 9 & \\
\hline \multirow{2}{*}{\multicolumn{4}{|c|}{ Apgar score }} \\
\hline & & & \\
\hline 1 minute & $3.20(0.52)$ & $\begin{array}{l}4.95(0.52) \\
8.16(0.32)\end{array}$ & $\begin{array}{l}0 \cdot 024 \\
0.004\end{array}$ \\
\hline $\begin{array}{l}5 \text { minutes } \\
\text { Birthweight (g) }\end{array}$ & $\begin{array}{l}5 \cdot 67(0 \cdot 69) \\
1070(70)\end{array}$ & $\begin{array}{c}8 \cdot 16(0 \cdot 32) \\
1382(125)\end{array}$ & $\begin{array}{l}0.004 \\
0.039\end{array}$ \\
\hline $\begin{array}{l}\text { Birthweight (g) } \\
\text { Gestational age (week) }\end{array}$ & $27.4(0.64)$ & $\begin{array}{l}1382(125) \\
29.5(0.59)\end{array}$ & $\begin{array}{l}0.039 \\
0.021\end{array}$ \\
\hline Sex ratio (male:female) & $10: 5$ & $8: 11$ & NS \\
\hline \multicolumn{4}{|l|}{ Duration of ventilation (hours) } \\
\hline$<24$ & 0 & 3 & \\
\hline$>24$ & 15 & 16 & NS \\
\hline Maximum peak airway pressure $\left(\mathrm{cm} \mathrm{H}_{2} \mathrm{O}\right)$ & $25 \cdot 80(1 \cdot 40)$ & $24 \cdot 00(1 \cdot 10)$ & NS \\
\hline Lowest arterial $\mathrm{PaO}_{2}$ & $28 \cdot 3(1.68)$ & $36 \cdot 1(2 \cdot 56)$ & 0.017 \\
\hline Highest arterial $\mathrm{PaCO}_{2}$ & $67 \cdot 1(3 \cdot 43)$ & $60 \cdot 1(2 \cdot 41)$ & $0 \cdot 10$ \\
\hline Lowest arterial $\mathrm{pH}$ & $7 \cdot 11(0 \cdot 02)$ & $7 \cdot 17(0 \cdot 02)$ & $0 \cdot 12$ \\
\hline $\mathrm{FIO}_{2}(\%)$ & $82 \cdot 0(4 \cdot 57)$ & $75 \cdot 1(5 \cdot 38)$ & NS \\
\hline Pneumothorax & 2 & 0 & NS \\
\hline Pancuronium/morphine & 3 & 0 & 0.08 \\
\hline Inotropes & 6 & 0 & 0.004 \\
\hline Artificial surfactant (Exosurf) & 5 & 11 & NS \\
\hline
\end{tabular}

*Results are expressed number or mean (SE). NS=non-significant.

Mean values were compared using Student's $t$ test. Numbers were compared by $\chi^{2}$ distribution or Fisher's exact test. had not been properly placed on the baby's skin.

The infants received clinical care independently of this study (table). Pancuronium $(0 \cdot 1$ $\mathrm{mg} / \mathrm{kg})$ or morphine $(0.1$ to $0.2 \mathrm{mg} / \mathrm{kg})$ were given when deemed necessary to assist ventilation, if the infant was observed to be struggling against the ventilator and the arterial partial oxygen pressure was poorly maintained because of active expiration against the inspiratory phase of the ventilator cycle. Plasma or $5 \%$ albumin $(10-15 \mathrm{mg} / \mathrm{kg})$ was given slowly if the infant was considered to be poorly perfused, together with inotropic support (dopamine or dobutamine, $5-10 \mu \mathrm{g} / \mathrm{kg}$ / minute). The inotrope infusion was started at $2 \cdot 5-5 \cdot 0 \mu \mathrm{g} / \mathrm{kg} / \mathrm{minute}$ and increased at intervals. Exogenous surfactant (Exosurf 67.5 $\mathrm{mg} / \mathrm{kg}$ ) was administered into the endotracheal tube in the first 72 hours of age when oxygenation was considered to be inadequate despite increasing ventilatory support. Vitamin E (20 mg/kg) was administered intramuscularly routinely after admission to the unit.

birth. The infants were an unselected group who were eligible for entry into the study if they had an umbilical artery catheter in place in the first few hours after birth, if they had no obvious congenital malformation, and if a neonatal monitor designated for research was available.

MEAN ARTERIAL BLOOD PRESSURE, HEART RATE, AND SKIN TEMPERATURE MONITORING For each infant the MABP, heart rate, and skin temperature were continuously recorded on a neonatal monitor (Hewlett Packard monitor, Model 78834A). Blood pressure was monitored via an arterial catheter that incorporated an oxygen electrode and a side lumen which was used for measuring blood pressure. Coupled to the catheter was a pressure transducer from which blood pressure signals were relayed to the neonatal monitor. Continuous monitoring of skin temperature and heart rate was carried out using skin electrodes attached to the neonatal monitor. For measurement of the skin temperature a skin electrode incorporating a metal plate was placed on the anterior abdominal wall. The metal plate was attached to a thermistor connected to the neonatal monitor.

Electrocardiogram (ECG) electrodes were attached to the right and left chest wall and the right lower limb. The heart rate was calculated from the ECG which was continuously displayed on the neonatal monitor alongside the skin temperature and blood pressure. The neonatal monitors were interfaced to a microcomputer (Hewlett Packard, Model Vectra ES12). Every 15 minutes the MABP, heart rate, and skin temperature were recorded on a floppy disk. These recordings were carried out daily in the first 10 days after birth, unless the infant had died at an earlier age. Occasionally recordings were missed because of: occlusion of the intra-arterial catheter or air in the catheter; removal of electrodes whilst the baby was being $x$ rayed; or because the thermistor

\section{CRANIAL ULTRASOUND SCANS}

These were carried out daily during the study period using an Acuson 128 sector scanner with a multihead probe; 3.5-7.5 $\mathrm{MHz}$. During each scan the ultrasound probe was placed over the infant's fontanelle. It was initially positioned in the coronal plane and angled towards the face and then towards the occiput. The probe was later rotated through 90 degrees and aligned along the sagittal suture. The lateral ventricles were seen in the sagittal section by angling the probe to the right and left. The scans were analysed on the same day. PVH was confirmed by the presence of an area of echogenicity in the germinal matrix of the subependymal region. Some haemorrhages extended into the ventricles or into the substance of the brain. Areas of intraparenchymal echodensities were followed up; in some there was complete resolution while in the remaining areas the development of cysts was noted.

\section{STATISTICS}

For each day's recording of MABP, heart rate, and skin temperature, the medians and 10-90 centile ranges of the 9615 minute values were calculated. For MABP, a statistic analogous to the coefficient of variation was calculated as: 10-90 centile range/median. This was analysed after transformation to logarithms to allow for its skew distribution. The correlation coefficient between MABP and heart rate was calculated for each day's results.

It was considered that the variables of interest might be affected by postnatal age, gestational age, and birthweight. Investigations of this are complicated by the fact that postnatal age varies within infants while the other two measures vary among infants. The analysis was therefore done in two stages. First, the dependence on postnatal age was 


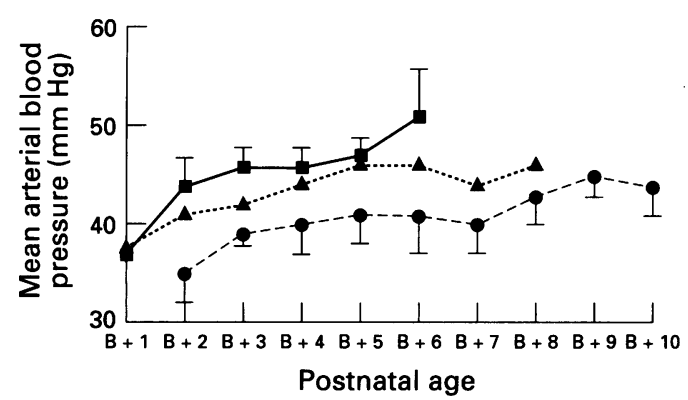

Figure 1 Mean (SE) arterial blood pressure - -1 in light $(<1.0 \mathrm{~kg}), \Delta . . \Delta$ medium $(1.0-1.5 \mathrm{~kg})$, and heavy $(>1.5 \mathrm{~kg})$ infants without $P V H$ in the first 10 days after birth. $B+1$, day 1 after birth; $B+2$, second day after birth, etc. Blood pressure is not shown if the number of babies in the subgroup is less than three.

investigated by fitting parallel regression lines to the infants without PVH. If there was evidence of a dependence on postnatal age, the results for all the infants were adjusted to a postnatal age of 5 days using the common slope, b; otherwise the mean of the available values was calculated. The difference between the infants with or without PVH was then studied by an analysis of covariance, using gestational age and birthweight as potential covariates.

\section{Results}

Of the 34 infants, 15 (44\%) developed a PVH. In 11 this was diagnosed in the first four days after birth, including four infants with a subependymal haemorrhage, three with an intraventricular haemorrhage and dilated ventricles, and four with an intraventricular haemorrhage and periventricular infarction (leucomalacia). The remaining four of the 15 infants had haemorrhages diagnosed between 6 and 9 days of age, including one with a subependymal haemorrhage, two with an intraventricular haemorrhage and dilated ventricles, and one with an intraventricular haemorrhage and periventricular leucomalacia. The five infants with periventricular leucomalacia later developed cystic lesions. None of the infants without PVH had similar ischaemic brain damage.

The table shows the clinical conditions of the infants in the first 10 days of life. Infants who developed a PVH had significantly lower Apgar scores at one and five minutes of age and they had a significantly lower birthweight and gestational age (Student's $t$ test). Infants who did not develop a PVH were, therefore, in a better condition at birth than the others in whom PVH was subsequently diagnosed by ultrasound scanning. The duration of ventilation, the maximum peak airway pressure, and the maximum $\mathrm{FIO}_{2}$ were not significantly different, but the severity of the respiratory distress syndrome seemed to be greater in infants who developed brain haemorrhages, as judged by the lowest arterial $\mathrm{PO}_{2}(\mathrm{p}=0 \cdot 017)$, highest arterial $\mathrm{PCO}_{2} \quad(p=0 \cdot 10)$, and lowest arterial $\mathrm{pH}(\mathrm{p}=0 \cdot 12$, Student's $t$ test). Six of these infants who developed a PVH had received plasma and inotrope $(p=0 \cdot 004)$.

As there were differences in birthweight and gestational age between the two groups of infants, a straightforward comparison between them in terms of MABP, heart rate, and skin temperature would be difficult to interpret. Therefore, the possible effect of birthweight, gestational age, and postnatal age would need to be assessed.

\section{MEAN ARTERIAL BLOOD PRESSURE}

The daily median of MABP $(\mathrm{mm} \mathrm{Hg}$ ) in infants without $\mathrm{PVH}$ was investigated by dividing the infants into light $(<1 \mathrm{~kg})$, medium $(1-1.5 \mathrm{~kg}$ ), and heavy $(>1.5 \mathrm{~kg}$ ) subgroups (fig 1). A plot of mean (SE) values against postnatal age in the three subgroups showed a rise in blood pressure with postnatal age and with the mean birthweight of the subgroup. Regression analysis indicated that the MABP increased very significantly with postnatal age, the regression coefficient being +1.255 $\mathrm{mm} /$ day ((SE 0.159); $\mathrm{p}<0.001$ ). When the subject means adjusted to day 5 were studied, there was no significant regression on gestational age but a highly significant regression on birthweight, both on the day of the PVH $(+6.13 \mathrm{~mm} / \mathrm{kg}$, (SE 2.21); $\mathrm{p}<0.02)$, and on the preceding day $(+6.67 \mathrm{~mm} / \mathrm{kg}$ (SE 1.59); $\mathrm{p}<0.01$ ). After allowing for this - that is, adjusting the subject means to postnatal age on day 5 and birthweight of $1.25 \mathrm{~kg}$ - no significant differences were found between both groups either on the day before PVH (mean difference $=-1.57 ; 95 \%$ confidence inter$\mathrm{val}=-4.80,+1.67)$ or on the day of $\mathrm{PVH}$ (mean difference $=-0.64 ; 95 \%$ confidence interval $=-4.93,+3 \cdot 65$ ).

When the logs of the coefficients of variation were studied, there was no evidence of any dependence on postnatal age, gestational age, or birthweight. There was a significant difference between the groups on the day of the $\mathrm{PVH}$ (mean ratio of $\mathrm{CV}_{\mathrm{PVH}} / \mathrm{CV}_{\text {non-PVH }}:=1 \cdot 31$; $95 \%$ confidence interval $=1.06,1.62 ; p<0.05)$ : on the previous day the difference was in the same direction but not significant (mean ratio $=1 \cdot 18 ; 95 \%$ confidence interval $=0.91$, 1.53).

\section{HEART RATE}

For daily median of heart rate (beats per minute) the mean result for the three subgroups of infants without PVH based on weight is shown in fig 2 (SEs have not been inserted for reasons of clarity). Regression analysis showed no evidence of any consistent

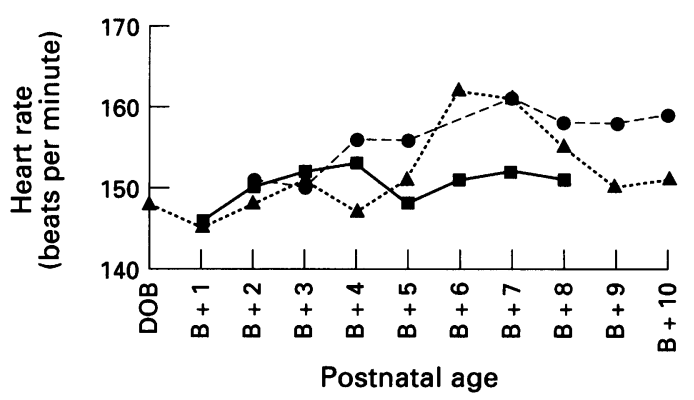

Figure 2 Mean heart rate in light, medium, and heavy infants in the first 10 days of life; details as in fig 1 . 


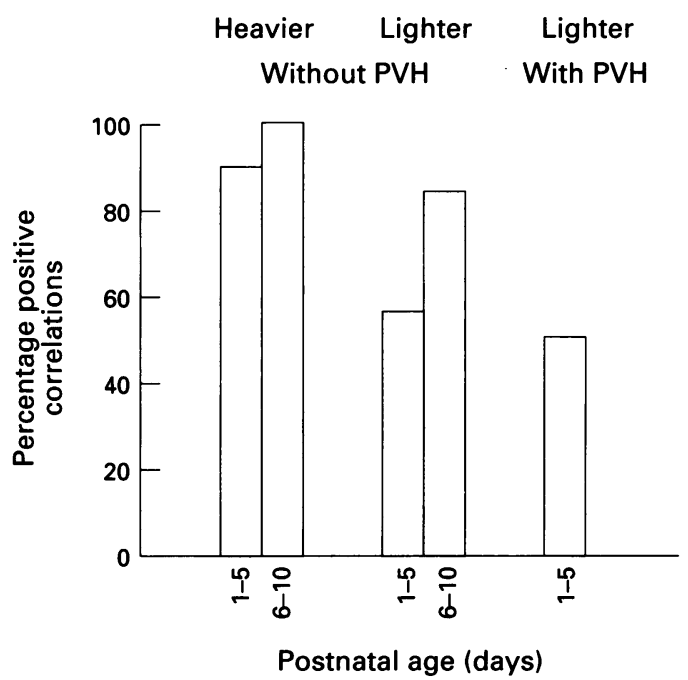

Figure 3 Percentage of total correlations between the 96 15 minute recordings of heart rate and $M A B P$ that are positive in infants with and without $P V H$ showing relation to birthweight and postnatal age.

increase or decrease in heart rate with postnatal age. When the means of the heart rate values were studied, there was no significant correlation with gestational age or birthweight, but there was a suggestion that heart rate was increased in the infants with PVH. Thus the mean difference between the groups on the day before PVH was $+9 \cdot 1$ beats/minute, PVH group higher $(95 \%$ confidence interval $=+0.5$, $+17.7 ; \mathrm{p}<0.05)$ and on the day of $\mathrm{PVH}$ this was $+7 \cdot 1$ beats/minute PVH group higher $(95 \%$ confidence interval $=-0.5$, $+14 \cdot 7 ; \mathrm{p}<0 \cdot 10)$.

\section{SKIN TEMPERATURE}

There was a suggestion that the skin temperature fell slightly with increasing postnatal age the regression coefficient was $-0.0152^{\circ} \mathrm{C} /$ day (SE $0 \cdot 0083 ; \mathrm{p}<0 \cdot 10$ ). After adjustment to 5 days' postnatal age there were no significant differences between the groups with or without PVH. Thus the mean difference on the day before $\mathrm{PVH}$ was $+0.07^{\circ} \mathrm{C}(95 \%$ confidence interval $=-0 \cdot 10,+0 \cdot 23)$ and on the day itself, this was $-0.06^{\circ} \mathrm{C}(-0.23,+0 \cdot 11)$.

\section{CORRELATION BETWEEN DAILY HEART RATE} AND BLOOD PRESSURE

Figure 3 shows the positive correlations between heart rate and MABP expressed as a percentage of the total correlations (positive and negative). In infants without PVH there was a tendency for the correlations to be positive more frequently in the heavier than in the lighter subgroup. For this analysis infants were divided by a median split $(1.3 \mathrm{~kg})$ into two subgroups. Of the 15 infants who developed a PVH 11 did so on days 1 to 5 ; nine of these were under $1.3 \mathrm{~kg}$. Statistically, the positive correlation between MABP and heart rate tended to increase with postnatal age (with a slope, $b=0.0217 /$ day, SE 0.0126; $p=0.10)$. After allowing for this, there was a significant increase in positive correlation with increasing birthweight, both on the day before (with a slope, $b=0.205 / \mathrm{kg}$, SE $0.069 ; p=0.001)$ and on the day of PVH (with a slope, $b=0 \cdot 196 / \mathrm{kg}$, SE $0.068 ; p<0.02$ ). There was no evidence of any consistent difference between the nonPVH and PVH groups when the effects of postnatal age (standardised to day 5) and birthweight (standardised to $1.25 \mathrm{~kg}$ ) were taken into account. The mean difference in correlations between the groups on the day before PVH was -0.032 ( $95 \%$ confidence interval $=-0.182,+0.118)$ and on the day itself was $-0.034(-0 \cdot 169,+0 \cdot 101)$. Thus the haemorrhages had taken place irrespective of the correlations between heart rate and blood pressure.

There were five deaths, all associated with PVH. All surviving infants with or without PVH were followed up for 13 to 23 months. One survivor in the PVH group with a history of intraventricular haemorrhage, dilated ventricles, and periventricular cysts developed cerebral palsy. By contrast, none of the survivors without PVH did so.

\section{Discussion}

This study has shown that newborn infants who developed a PVH had a lower birthweight and gestational age, lower Apgar scores, and developed a greater severity of respiratory distress syndrome. In such infants Miall-Allen et al have attributed the development of brain haemorrhage, ischaemic cerebral lesions, or death to an MABP of $<30 \mathrm{~mm} \mathrm{Hg}(4 \mathrm{kPa})$ for over an hour. ${ }^{11} \mathrm{We}$ used data collected on infants who did not develop a PVH to show that blood pressure in the first few days after birth is related to birthweight and postnatal age. Using this information we showed also that the lower MABP recorded in infants with a PVH is consistent with their lower birthweight. Six infants in the PVH group had received inotropic support (table). They developed a haemorrhage although their blood pressure was well maintained before and when a PVH was diagnosed, but we cannot exclude the possibility that an MABP of $<30 \mathrm{~mm} \mathrm{Hg}$ had occurred earlier when treatment was initiated with plasma and inotropic drugs.

The MABP, heart rate, and skin temperature recordings we carried out may reflect circulatory transitions as the preterm infant adapts to life outside the uterus. The precise mechanisms which determine the level of blood pressure after birth are not entirely understood. ${ }^{15}$ The left ventricle takes over the perfusion of tissues which were supplied by the right ventricle in utero. The observed postnatal increase in blood pressure may reflect raised cardiac output after birth, principally to sustain systemic perfusion overall and partly to sustain increased oxygen metabolism to maintain body temperature. ${ }^{15}$ Experimental studies suggest that the neonatal circulation may be subjected to various influences, including baroreflexes, ${ }^{16}$ arterial chemoreceptors, ${ }^{17}$ sympatho-adrenal activity 1819 and of the renin-angiotensin system. $^{2021}$ Our study has emphasised the effects of birthweight, gestational age, and postnatal age on blood pressure. 
Recently, blood pressure and heart rate were found to be affected by gestational age. ${ }^{22}$ In infants of under 34 weeks' gestation there was a negative correlation - that is, the two variables were in antiphase - but after 34 weeks' gestation infants shared a positive correlation, indicating that the two variables were in phase. ${ }^{22}$ We have shown that this relation is also affected by postnatal age. In our groups of infants the correlation between the daily medians of heart rate and blood pressure was more likely to be positive over a less precise period than that previously reported. ${ }^{22}$ We found a rise in the proportion of positive correlations between heart rate and MABP with postnatal age and birthweight.

Cunningham et $a l^{22}$ suggest that asynchrony in the development of the autonomic nervous system may account for this transition in phase relation. However, this would ignore a plethora of other possible influences, including the adaptation of chemo- and baroreceptors to extra-uterine life, changes in the central nervous system control mechanisms in the face of increased input from these receptors, or the secretion of some endocrine factor which may bias the system to a positive phase relation. ${ }^{23}$ In our study the synchronous relation of heart rate to MABP in infants with PVH was similar to that in a comparable group of infants without PVH. Brain haemorrhage had taken place irrespective of the percentage of positive correlations between heart rate and blood pressure.

We found that the CV for MABP was not influenced by postnatal age, gestational age, or birthweight: but it was higher for the PVH group on the day before and on the day the haemorrhage was diagnosed. Previous studies have not considered the influence of birthweight and postnatal age on the $\mathrm{CV}$ for blood pressure, although the mechanisms regulating these variations are not completely understood. ${ }^{714}$ In fetal animals such variability in blood pressure may reflect fluctuations in sympathetic tone, and pharmacological blockade of sympathetic activity greatly attenuates the naturally occurring variability in heart rate and MABP. ${ }^{24}$ As infants who developed a PVH had lower Apgar scores and a greater severity of respiratory distress syndrome, hypoxia and acidosis may have made them more prone to changes in blood pressure and caused an increase in heart rate. We suggest that this may occur partly through increasing sympathetic tone.

During periods of hypoxia, Jansen et al found that blood flow to the cerebrum, midbrain, medulla, pons and cerebellum was increased. ${ }^{25}$ The cerebral vasculature of the fetus does not appear to autoregulate, in that during hypoxia there is a linear relation between systemic blood pressure and cerebral blood flow. ${ }^{26}$ In similar circumstances it is reasonable to speculate that impaired cerebrovascular autoregulation had resulted in PVH in our infants. The infant's apparent propensity for increases in cerebral blood flow to dangerous levels may have occurred with the 'normal' rise in blood pressure which takes place after birth due to a pressure passive state of the cerebral circulation. ${ }^{8}$ Thus the postnatal increase in MABP (fig 1) may be delivered to the germinal layer matrix when there is superimposed hypoxia and cause disruption of thin-walled blood vessels. ${ }^{9} 10$

It seems to us that infants who developed a PVH had been born too soon and instability in blood pressure may have been as a result of their immaturity, adding to their difficulty in adapting to an extra-uterine environment. Otherwise, their MABP and skin temperature were similar to those in infants of greater gestational age and without a $\mathrm{PVH}$, taking into account their bodyweight, gestational age, and postnatal age. By contrast, there was a higher heart rate and CV for MABP than in infants without a PVH. The extent to which this would influence cerebral blood flow velocity requires further study. Although it remains our view that hypotension should be treated, we did not find that therapeutic intervention with plasma and inotropic drugs prevented the development of PVH.

We are grateful for help received from the medical and nursing staff in the Neonatal Medical Unit, and from Dr S Russell and Dr S Rimmer in the Department of Radiology, St Mary's Dr S Rime The Department Hospital. The help we also received from consultant paediatricians at other hospitals in studying outcome in our infants is his helpful comments, Professor M J R Healy for help with statistics, and Mrs Elaine Evans for secretarial assistance.

1 Weindling AM. Blood pressure monitoring in the newborn Arch Dis Child 1989; 64: 444-7.

2 Watkins AMC, West CR, Cooke RWI. Blood pressure and cerebral haemorrhage and ischaemia in very low birthweight infants. Early Hum Dev 1989; 19: 103-10.

3 Bada HA, Korones SB, Perry EG, Arheart KL, Ray LD, Ponayrous M, et al. Mean arterial blood pressure changes in premature infants and those at risk for intraventricular in premature infants and those at risk for int

4 Dykes FD, Lazzara A, Aliman P, Blumstein B, Schwartz J, Braun AW. Intraventricular haemorrhage: a prospective Braun AW. Intraventricular haemorrhage: a prosp

5 Cooke RWI. Factors associated with periventricular haemorrhage in very low birth weight infants. Arch Dis Child 1981; 56: 425-31.

6 Levene MI, Fawer CL, Lamont RF. Risk factors in the development of intraventricular haemorrhage in the preterm neonate. Arch Dis Child 1982; 57: 410-7.

7 Perlman JM, McMenamin JB, Volpe JJ. Fluctuating cerebral blood flow velocity in the respiratory distres syndrome. N Engl f Med 1983; 309: 204-9.

8 Lou CL, Lassen NA, Friis-Hansen B. Impaired autoregulation of cerebral blood flow in the distressed newborn infant. F Pediatr 1979; 94: 118-21.

9 Pape K. Etiology and pathogenesis in intraventricular haemorrhage in newborns. Pediatrics 1989; 84: 382-5.

10 Hambleton G, Wigglesworth JS. Origin of intraventricular haemorrhage in the preterm infant. Arch Dis Child 1976; 51: 651-9.

11 Miall-Allen VM, De Vries LS, Whitelaw AGL. Mean arterial blood pressure and neonatal cerebral lesions. Arch Dis Child 1987; 62: 1068-9.

12 Rennie JM, Smith M, Morley CJ. Cerebral blood flow velocity variability in infants receiving ventilation. Arch Dis Child 1987; 62: 1247-51.

13 Omar SY, Greisen G, Ibrahim MM, Youssef AM, FriisHansen B. Blood pressure responses to care procedures in ventilated preterm infants. Acta Paediatr Scand 1985; 74: 920-4.

14 Miall-Allen VM, deVries LS, Dubowitz LMS, Whitelaw AGL. Blood pressure fluctuation and intraventricular haemorrhage in the preterm infant of less than 31 weeks' haemorrhage in the preterm infant of

15 Walker AM. Circulatory transitions at birth and the control of the neonatal circulation. In: Hanson MA, Spencer JAD, Rodeck $\mathrm{CH}$, eds. Fetus and neonate: physiology and clinical applications. Volume 1. The circulation. Cambridge: Cambridge University Press, 1993: 160-6.

16 Dawes GS, Johnston BM, Walker DW. Relationship of arterial blood pressure and heart rate in fetal, newborn and adult sheep. F Physiol (Lond) 1980; 309: 405-7.

17 Hanson MA. The importance of baro- and chemoreflexes in the control of the fetal cardiovascular system. $f$ Dev Physiol 1988; 10: 491-511.

18 Padbury JF, Diakomanolis ES, Hobel CJ, Perlman A, Fisher DA. Neonatal adaptation: sympathoadrenal response to umbilical cord cutting. Pediatr Res 1981; 15: 1483-7.

19 Padbury JF, Pole DH, Newnham JP, Lam RW. Neonatal adaptation: greater sympathoadrenal response in preterm adaptation: greater sympathoadrenal response in preterm than full 
20 Heymann MA, Iwamoto HS, Rudolph AM. Factors affectsystemic circulation. Ann Rev Physiol 1981; 43: 371-83.

21 Broughton-Pipkin F, Symond EM. Renin-angiotensin system in early life. In: Beard RW, Nathanielsz PW, eds. Fetal physilogy and medicine 2 nd Butterworths, 1984: 459-80.

22 Cunningham S, Deere S, McIntosh N. Cyclical variation of blood pressure and heart rate in neonates. Arch Dis Child blood pressure and

23 Hanson MA. The control of the heart rate and blood pressure in the fetus: theoretical considerations. In: Hanson MA, Spencer JAD, Rodeck CH, eds. Fetus and neonate: physiology and clinical applications. Volume 1. The circulation. Cambridge: Cambridge University Press, 1993: 1-22.

24 Segar JL, Merrill DC, Smith BA, Robillard JE. Role of sympathetic activity in the generation of heart rate and arterial pressure variability in fetal sheep. Pediatr Res 1994; 35: pressure

25 Jensen A, Kemzel W, Kastendieck E. Fetal sympathetic activity, transcutaneous $\mathrm{PO}_{2}$ and skin blood flow during 26 Tweed WA, Cote J, Pash M, Lou H. Arterial oxygenation Tweed WA, Cote J, Pash M, Lou H. Arterial oxygenation
determines auto-regulation of cerebral blood flow in the fetal lamb. Pediatr Res 1983; 17: 246-9. 